\title{
A CONSTRUÇÃO DO DISCURSO DE POBREZA EM RELATÓRIOS OFICIAIS: A PROVÍNCIA DO ESPIRÍTO SANTO NA PRIMEIRA METADE DOS OITOCENTOS
}

\author{
THE CONSTRUCTION OF THE POVERTY DISCOURSE IN OFFICIAL \\ REPORTS: THE PROVINCE OF ESPÍRITO SANTO IN THE FIRST \\ HALF OF THE NINETEENTH CENTURY
}

DOI: http//dx.doi.org/10.15448/21778-3748.2018.2.27523

\author{
Solange Faria Prado \\ Doutora - UFES \\ solfprado@gmail.com
}

\begin{abstract}
RESUMO: Partindo de análise de relatórios presidenciais da província do Espírito Santo na primeira metade dos oitocentos e dos resultados de pesquisas desenvolvidas no Programa de Pós-Graduação em História da Universidade Federal do Espírito Santo (UFES), este artigo tem por objetivo discutir a construção do discurso de pobreza tão usado nos relatórios presidenciais provinciais, buscando as razões para sua sedimentação e trazendo evidências que possam nos permitir compreender sua economia para além da teoria dos "ciclos econômicos" tão em voga até a primeira metade do século XX. No entanto, ao proceder às análises, o que se depreende dos relatórios provinciais, tal qual as demais províncias, é que a província do Espírito Santo não era tão pobre quanto se alegava, mas, como qualquer outra, dependia da força política do presidente do momento. Fundamentado na História Regional, este artigo buscará mostrar que é possível desconstruir o discurso de pobreza por tanto tempo sustentado na história capixaba.
\end{abstract}

Palavras-chave: Economia. Província do Espírito Santo. Pobreza.

\begin{abstract}
Based on the analysis of the presidential reports of the province of Espírito Santo in the first half of the nineteenth century and the results of research carried out in the History postgraduate studies program at the Federal University of Espírito Santo - UFES, this article aims to discuss the construction of the discourse of poverty so used in the provincial presidential reports seeking the reasons for its sedimentation and bringing evidence that can allow us to understand its economy beyond the theory of "Economic Cycles" so in vogue until the first half of the twentieth century. However, in carrying out the analyses, what can be gathered from the provincial reports is that, like as with the other provinces, the province of Espírito Santo was not as poor as it was claimed, but like any other province it depended on the political strength of the president of the moment. Based on Regional History, this article will seek to show that it is possible to deconstruct the discourse of poverty for so long sustained in the History of Espírito Santo.
\end{abstract}

Keywords: Economics. Province of Espírito Santo. Poverty.

A história econômica brasileira baseada na teoria dos "ciclos econômicos", tão em voga até os anos 50 do século passado, poderia representar o país como sendo uma cornucópia que extravasava riquezas várias, já que não apresentava nenhuma das particularidades das regiões 
que o compõem. Embora seja louvável o esforço de Roberto Simonsen ao debruçar-se sobre a trajetória do fenômeno econômico, adaptando conceitos europeus à realidade brasileira, contribuindo para que outros estudiosos entrassem nessa seara, o extenso território brasileiro foi visto de forma homogênea, deixando-se de lado as particularidades de cada região. Como lembra Capistrano de Abreu (1988), o Brasil, desde a colônia, figura-se como um mosaico aglutinador de diferentes regiões em seus aspectos fauno-florísticos e étnicos; somente a língua e a religião católica, impostas pelos colonizadores, dão-lhes uma característica comum. Buscando imagens mais contemporâneas, pode-se apresentar a heterogeneidade brasileira como aquela elaborada por Francisco de Oliveira (2003), segundo o qual as regiões, como um todo, seriam como um arquipélago, cujas ilhas são articuladas e atadas pelo fino fio do mercado externo. Ou ainda como um ornitorrinco, que, ao cabo, é um mosaico de várias espécies animais.

Com uma economia fundamentada na agroexportação, ao lado da posse de largas extensões de terra que eram trabalhadas por uma massa de escravos negros, as peculiaridades agrícolas regionais dinamizavam o mercado interno brasileiro, fortalecendo e sustentando o mercado externo. Tal dinamismo testemunha o "sentido da colonização" tratado por Caio Prado Junior (1961) quando assevera que a colonização brasileira foi um empreendimento comercial mercantilista nascido para atender às demandas europeias por produtos tropicais.

Os estudos empreendidos por Marcus Antonio Croce (2015) demonstram que os diversos produtos que fizeram parte do rol de exportação da balança comercial brasileira, especificamente durante os oitocentos, atestam que cada região tinha suas peculiaridades econômicas e socioterritoriais que, promovendo certo dinamismo ao mercado interno por vezes. Tais singularidades de produção foram omitidas pela insistência na análise fundamentada na teoria dos ciclos econômicos, cujas bases comuns em todas as regiões eram o latifúndio em sistema de plantation, ou seja, extensão de terras trabalhada por escravos negros submetidos ao poder do senhor e a monocultura para exportação.

Uma leitura atenta da história econômica brasileira mostra como as especificidades regionais garantiram o mercado exportador brasileiro mais diversificado. Em outras palavras, como nos aponta Croce (2015, p. 1), não houve aclamação de "[...] apenas um produto como referência para a economia de todo o conjunto brasileiro como [...] [querem] autores que descrevem a economia brasileira no século XIX amarrada a ciclos sazonais". Estudar a economia do Brasil apenas pelo sistema de plantation é, no dizer de Sheila de Castro Faria (1998), tornar pequeno o complexo universo econômico do Brasil. 
Diante disso, havemos de nos questionar sobre a economia desenvolvida na província do Espírito Santo na primeira metade dos oitocentos, já que, a partir da segunda metade destes, o café lhe proporcionaria relativo destaque no conjunto brasileiro. A província do Espírito Santo, no universo da região Centro-Sul, sempre fora notabilizada pela sua situação de pobreza, tão largamente citada em textos de viajantes europeus, documentos e relatórios governamentais. Entretanto, o que de fato ocorria com a província capixaba? Qual era o significado de pobreza para os contemporâneos? O que se arrecadava em impostos e taxas cobria suas despesas? O que se fez, afinal, para a mudança desse cenário?

Para tentar responder tais questões, para fins deste trabalho, iremos nos valer de trabalhos publicados sobre o assunto, relatórios de presidentes de província, bem como dos resultados de pesquisas desenvolvidas no Programa de Pós-Graduação em História da Universidade Federal do Espírito Santo (UFES). Desta maneira, além de buscarmos respostas aos questionamentos elencados, nosso objetivo é reunir evidências que nos permitam compreender a permanente referência à pobreza da província durante a primeira metade do século XIX. Para tanto, o exercício proposto se encaixa nos estudos de História Regional desenvolvido por Barros (2005, p. 152), que nos oferece certa “[...] iluminação em detalhe de grandes questões econômicas, políticas, sociais e culturais que até então haviam sido examinadas [...]" em contextos mais amplos, trazendo à tona singularidades locais que nos faculta trilhar melhor pela história da província do Espírito Santo.

\section{ESPÍRITO SANTO: UMA CAPITANIA SOBREVIVENTE?}

Com várias tribos indígenas dificultando a ocupação e colonização do interior da capitania de Vasco Coutinho até meados dos oitocentos, a região do atual Estado do Espírito Santo, como as demais capitanias e posteriores províncias, não teve um processo de colonização pacífico. Ocupadando, primeiramente, uma pequena faixa litorânea que, conforme Auguste Saint-Hilaire (1936), não tinha mais do que quatro léguas de largura, seus colonizadores sofriam ataques dos aguerridos Botocudos, indígenas considerados muito bravos e também canibais.

Mesmo com os entraves proporcionados por indígenas hostis, aos olhos dos colonizadores, a capitania do Espírito Santo teve sua economia desenvolvida, apesar da pouca ocupação europeia - que, até o século XIX, foi pequena. Segundo João Eurípedes Franklin Leal (1977), nos anos 80 do século XVI, havia cerca de seis engenhos na capitania que chegaram a produzir algo em torno de seis mil toneladas de açúcar. E sua população era um pouco maior que a do Rio de Janeiro, próximo a 180 colonos. Poucos anos antes, segundo o autor, com o 
desenvolvimento da capitania, chegou-se a criar uma alfândega, já que havia comercialização de produtos entre Vitória, Portugal e Angola.

No decorrer dos seiscentos, a capitania experienciou a decaída de sua economia. De acordo com Leal (1977), o depauperamento chegou ao ponto de ter facilitadas suas obrigações de enviar valores para Portugal no episódio do pagamento pela paz com a Holanda e o do dote da Infanta D. Catarina por ocasião de seu casamento com Carlos II da Inglaterra. O autor assevera ainda que "[a] crise econômica e financeira atingiu o ponto culminante em 1664, quando a receita dos dízimos atingiu apenas 400 mil réis, enquanto que a despesa era de dois mil cruzados" (LEAL, 1977, p. 04). Isso, porém, não quer dizer que somente a capitania do Espírito Santo passava por dificuldades.

Após a descoberta do ouro na região das Minas Gerais, a capitania do Espírito Santo, sob ordem da Coroa lusitana, constituiu-se em uma "barreira verde" que pretendia coibir a fuga de metais e pedras preciosas, reforçando a ocupação apenas na faixa litorânea. Essa política de proteção das minas de ouro empreendida pela Coroa, segundo a historiografia tradicional capixaba, travou a economia e, de maneira geral, impediu a ocupação do interior. No entanto, há novas análises historiográficas que apresentam que a inexistência de caminhos que ligassem as regiões também contribuiu para esse cenário.

Segundo pesquisa empreendida por Enaile Flauzina de Carvalho (2008) no Programa de Pós-Graduação em História da Universidade Federal do Espírito Santo (UFES), a proteção às minas proibindo o tráfego de pessoas e mercadorias, isolando a capitania do Espírito Santo, ocorreu por pouco tempo, uma vez que havia "[...] o vivo interesse da metrópole por essa porção colonial relegada a planos secundários durante séculos e que lhe conferia novo impulso, pelo menos do ponto de vista da administração" (CARVALHO, 2008, p. 39).

Tal informação é comprovada pela nomeação do Capitão de Fragata Antonio Pires da Silva Pontes por meio de decreto de 11 de novembro de 1797. Assim, já no limiar dos oitocentos, visando o desenvolvimento econômico e a ocupação do interior da capitania, Silva Pontes solicitou, por meio de ofício ao Secretário de Estado da Marinha e Ultramar, D. Rodrigo, Conde de Linhares, “[...] a abertura da navegação e do comércio através do Rio Doce, para tanto, fundou quartéis e promoveu obras no sentido de viabilizar a mineração" (CARVALHO, 2008, p. 40) e, consequentemente, a colonização da área.

Pouco antes do decreto do Bloqueio Continental e a vinda da Família Real para o Brasil, Silva Pontes foi substituído por Manoel Vieira da Silva de Albuquerque Tovar, que deu prosseguimento à política empreendida por Silva Pontes, atendendo aos desejos da Coroa 
Lusitana (DAEMON, 2010; OLIVEIRA, 2008; CARVALHO, 2008). M esmo politicamente contrariando as elites locais com algumas arbitrariedades, Tovar, no campo econômico, promoveu maior dinamismo ao comércio da capitania, evidenciando, segundo Carvalho (2008, p. 43), “[...] a capacidade exportadora de produtos como açúcar, algodão, farinha de mandioca, milho, arroz e aguardente; [...] [além] de navios [carregados] com madeiras para a construção naval, com destino a Portugal e ao Rio de Janeiro".

Um terceiro governador que, seguindo a política de desenvolvimento da colônia e também da capitania, deu continuidade aos incrementos econômicos da capitania com relativa importância foi Alberto Francisco Rubim. Este empreendeu obras públicas e aberturas de estradas, incentivou o desenvolvimento da lavoura e da mineração e promoveu a colonização e ocupação de territórios incultos por meio do estabelecimento de imigrantes no entorno da cidade de Vitória. É da sua gestão a colônia agrícola de Açorianos às margens do rio Santo Agostinho.

Embora pouco ou nada tenha resultado de seus feitos, Alberto Francisco Rubim, segundo Leal (1977, p.10) desenvolveu, em médio prazo, a possibilidade de um maior desenvolvimento da agricultura na região sul da província, especificamente no baixo Itapemirim. Ali

[...] a construção do quartel da Barca, que deu origem a Cachoeiro de Itapemirim, ligado ao litoral por duas estradas que atingiam Piúma e Muribeca, sempre patrulhadas em forma circular, protegia uma área triangular e dava condições ao florescimento de grandes propriedades agrícolas.

Todavia, será no governo de Rubim que florescerá a cultura do café, cuja produção, no início de sua gestão, será exportada, colocando o café como promessa de desenvolvimento econômico e ocupação da província. Uma produção advinda dos sertões do Rio Doce mudaria o cenário socioeconômico da província do Espírito Santo a partir da segunda metade dos oitocentos.

Como se depreende do exposto até o momento, a capitania e posterior província do Espírito Santo, do início de sua ocupação, no século XVI, até os primeiros anos do século XIX, antes da independência, teve uma economia que sofreu infortúnios, mas que chegou aos oitocentos com um "horizonte de expectativas" (KOSELLECK, 2006) que projetava transformações no futuro - transformações econômicas, financeiras e sociais esperadas para viabilizarem a entrada da província do Espírito Santo no hall da modernidade. 
Contudo, realizada a independência do jugo português, a província do Espírito Santo é praticamente abandonada, e todos os projetos que prospectavam um futuro melhor, ainda que em uma condição escravista colonial - a exemplo de seus congêneres na região Sudeste, que recebiam apoio político do governo central - caem por terra. Esse abandono, conforme Gabriel Bittencourt (1987, p. 15), “[...] relegou a terra capixaba a uma 'economia de sobrevivência' [...]”. Não obstante, havia, no norte da província, na cidade de São Matheus, um dinâmico comércio exportador para o mercado interno da farinha de mandioca que abastecia as províncias do Rio de Janeiro, de Minas Gerais e da Bahia (NARDOTTO, 1999); no sul, na vila de Itapemirim, havia, juntamente com o incipiente comércio do café, a extração e o comércio de madeira, especialmente para a Marinha Real.

\section{POBREZA COMO DISCURSO: PRESENÇA CONSTANTE NOS DOCUMENTOS GOVERNAMENTAIS CAPIXABAS}

Na História Social, deparamo-nos com várias concepções de pobreza. Segundo Lauro Mattei (2014), a concepção de pobreza vai desde aquela que se identifica com privações, seja monetária ou mesmo básica para a subsistência, até aquela que é definida por pobreza relativa, indicando que não apenas não há acesso a maiores rendas que possam promover maiores recursos materiais, promovendo o progresso, mas também a outros tipos recursos, como a educação. Por isso, neste tópico, buscaremos captar a concepção que acreditamos que tenha dado vazão ao discurso de pobreza tão propalado pelos documentos oficiais.

Assegurada a independência - que, conforme Caio Prado Junior (1993), foi operada a partir de manobras políticas capitaneadas pelas elites políticas brasileiras e da Metrópole--, deuse início à organização do Estado Nacional brasileiro. Todavia, antes da outorga da Constituição, em 1823, foram organizadas Juntas Provisórias cujos representantes deveriam, pelo voto, ascender à presidência. Na província do Espírito Santo, o primeiro presidente foi Ignácio Accioli de Vasconcelos, que assumiu seu posto no ano seguinte, 1824.

Carvalho (2008, p. 49, grifo nosso) nos noticia que, antes mesmo da independência, os memoriais da província do Espírito Santo,

[...] a partir de 1800 , dedicava[m]-se com mais veemência do que as [administrações] antecessoras, dos capitães-mores, no que refere aos assuntos concernentes ao processo de desenvolvimento do Espírito Santo, figurando a questão econômica, no meio político, como essencial para o cumprimento dos designo (sic) da administração portuguesa. [...] [buscando] novas fontes de 
riquezas para viabilizar a manutenção da monarquia, que passou a ter como sede administrativa o Rio de Janeiro, a partir de 1808.

Podemos observar, no fragmento acima, que o interesse da Coroa em desenvolver a província do Espírito Santo era para possibilitar a manutenção da monarquia. Para isso, providências foram tomadas: os presidentes provinciais deveriam proceder ao planejamento das divisões administrativas, fossem elas eclesiásticas e/ou civil, e foram escritos relatórios ou memoriais que diziam respeito aos feitos realizados à frente do governo, além dos aspectos concernentes à natureza, geologia, geografia, hidrografia e produção e dos aspectos fundiários e educacionais da província que presidiam.

Em 1840, veio a lume as memórias de Francisco Alberto Rubim, escritas em 1818 e publicadas em Lisboa. Nessas memórias, além de informar sobre os limites e sobre alguns dos povoados da então capitania, Francisco Rubim (1840) assinala a existência de 75 engenhos de açúcar e 65 engenhocas distribuídas nas três regiões da província, ou seja: havia 26 engenhos e 21 engenhocas na região norte, nas proximidades do Rio Doce; 24 engenhos e 22 engenhocas na região central, nas proximidades da vila de Vitória; e 25 engenhos, sendo oito deles engenhos reais, ${ }^{1}$ e 22 engenhocas na região sul, nas proximidades do rio Itapemirim e Itabapoana.

Sobre a capital, Vitória, Francisco Rubim (1840, p. 22, grifo nosso) faz uma interessante observação quando diz que:

[a]inda que não rica, é comtudo assento do governo, e cabeça da comarca; sua perspectiva bastante elegante, suas casas, pela maior parte, são de sobrado, e reformadas todas por um só gosto á moderna, e seus habitantes, os homens, se occupão no comércio, para o qual possuem embarcações costeiras, e nos differentes officios, e as mulheres em cozer e fiar.

Buscando um cotejamento entre fontes e atendendo ao objetivo deste trabalho, trazemos a Memoria Statistica da Provincia do Espírito Santo, de Accioli Vasconcellos (1978), do ano de 1828, que também nos traz informações sobre o que ocorria com a produção da então capitania do Espírito Santo. Embora ela tivesse sua agricultura considerada pelo autor como de subsistência e, ainda, que sua população vivesse em estado miserável, os apontamentos de Vasconcellos demonstram que o que era exportado pela capitania garantia a importação de outros gêneros necessários à sociedade capixaba. Portanto, havia pobreza, mas não uma pobreza absoluta.

${ }^{1}$ Diferentemente do engenho movido por tração animal, o engenho real era movido pela força d'água. 
De acordo com as memórias de Accioli de Vasconcellos, somente no ano de 1826 e 1827 foram exportados vários produtos, resultando no montante de 195:500\$000 réis. Todos os gêneros, importados ou exportados, no ano de 1828, foram pagos em dinheiro, num total de 183:510\$750 rs. Sendo assim, houve, no dito ano, um saldo de 11:989\$250 rs que poderíamos, talvez, considerar como sendo capital de giro do comércio. Essa afirmativa pode ser corroborada pela pesquisa de Carvalho (2008, p. 57), que constata que, no período, “[...] grande parte da população era composta por proprietários de bens rurais e urbanos [...] [concentrando] rendas nos ambientes agrícolas e comerciais, acumulando a designação de agricultores e/ou lavradores, com a de negociantes".

A análise dos dois documentos é interessante, se não bem curiosa. Sendo governador e presidente de província no período anterior e pós-independência, respectivamente e, ainda aqueles que ficaram no poder por mais de cinco anos ${ }^{2}$, é fácil detectar a quem são dirigidos os discursos. Enquanto Rubim radiografava a capitania, demonstrando seu florescimento à Coroa, Accioli fazia questão de pontuar o estado de pobreza da província que, depois da anexação, em 1821, de Campos dos Goytacazes à província do Rio de Janeiro, perdia boa parte de suas rendas. Para pagamento de dívidas e despesas da província capixaba, o único remédio era recorrer ao governo central. Accioli foi enfático ao dizer que "[é] preciso enfim que S. M. Imperial esteja cabalmente ciente de que esta Província é a mais miserável do Império: Não tem agricultura nem comércio: seus habitantes são pobríssimos" (OLIVEIRA, 2008, p. 329). Ora, como poderia ser considerada "a mais miserável” província se, pouco tempo depois, em suas memórias, ele trazia a informação de que havia agricultura e um promissor comércio?

Rubim, ao escrever suas memórias, apresentava à Coroa - que cumpria seu papel promovendo o desenvolvimento da capitania para garantir a manutenção da monarquia instalada no Rio de Janeiro - um cenário de prosperidade e certa abundância, já que havia 75 engenhos e 65 engenhocas. Accioli, por sua vez, ao governar a província após a independência e auxiliando na construção do Estado Nacional, demonstra, em oficio dirigido ao Ministério do Império, seu descontentamento pela separação de Campos dos Goytacazes, alegando a extrema pobreza da província do Espírito Santo, já que não havia receita para cumprir com suas responsabilidades, especificamente o vencimento de soldos e o trabalho de "civilização" dos indígenas, que poderiam assolar a agricultura e agricultores.

\footnotetext{
${ }^{2}$ Francisco Alberto Rubim, logo após a capitania do Espírito Santo se tornar "independente" da capitania da Bahia, governou-a de 1812 a 1819. Ignácio Accioli de Vasconcelos, após a independência, ainda no Primeiro Reinado, governou de 1824 a 1829. Para maiores informações conferir Olveira (2008).
} 
Notamos que o oficio de Accioli contradiz suas memórias, pois, ao apresentar que importação e exportação eram pagas em dinheiro e, ainda, que o comércio, na sua visão, parecia ser ativo, pensamos que a população não era tão pobre quanto se alegava, o que nos leva a afirmar que poderia haver pobreza. Porém, como nos ensina Townsend (1993 apud CODES, 2005), seria uma pobreza de privação relativa, já que, nas vilas São Mateus e Itapemirim, em Vitória, considerando o ambiente econômico das áreas citadas e o contingente de escravos, havia agricultura e comércio bem ativos.

Além disso, é de se questionar: embora saibamos que ambos os discursos têm endereço certo, o que aconteceu com os engenhos e as engenhocas apontados por Rubim? Será que, em dez anos, todos foram à bancarrota? Por certo, havia divergências de interesses e ideologias entre os governantes, especificamente no que tange ao conceito de pobreza.

Passado o primeiro momento pós-independência, estancada a corrente absolutista que culmina na abdicação de Pedro I e inaugurada uma fase em que os brasileiros tomavam as rédeas do país, era necessário continuar a montagem das diretrizes para o Estado Nacional. Entretanto, a instabilidade política e a situação econômica do país como um todo deu aos que estavam à frente do governo regencial a oportunidade, conforme Raymundo Faoro (1958), de elaborar mudanças que descentralizavam o governo, proporcionando a constituição de uma monarquia federativa, cujo principal arranjo foi a consolidação do Ato Adicional de 1834, ${ }^{3}$ promovendo, assim, certa autonomia às províncias.

Sem entrar em detalhes sobre os efeitos dos atos do Ato Adicional, atendendo aos objetivos deste trabalho, vamos nos ater às questões econômicas e fiscais que, segundo pesquisas de Eucélia Maria Agrizzi Mergár (2011. p. 61), tal emenda deu às províncias a condição de

[...] fixar as despesas municipais e provinciais e os impostos para elas necessários, desde que não prejudicassem as rendas gerais, o que na prática, significava que, embora existisse um número excessivo de tributação, esse não conseguia atender às demandas locais, por estar se constituindo, nesse momento um desenvolvimento fiscal autônomo nas províncias e por ser ainda incipiente, não se traduzia nos frutos necessários.

\footnotetext{
${ }^{3} \mathrm{O}$ Ato Adicional de 1834 foi uma emenda à Constituição de 1824 que buscou conciliar as diferentes tendências políticas na direção do país, ou seja, foi uma tentativa de conciliar as ideias dos moderados, exaltados e conservadores. No que tange à arrecadação, o Ato Adicional garantia legislar sobre as receitas e despesas. Para maiores esclarecimentos, sugerimos consultar CARVALHO (2014) e MERGÁR (2011).
} 
Não obstante a autonomia conquistada, em várias províncias, houve manifestações de descontentamento, ${ }^{4}$ que resultaram na reforma e consequente anulação de algumas das atribuições concedidas às províncias pelo Ato Adicional, promovendo a promulgação da Lei de Interpretação do mesmo ato. Se a Lei de Interpretação promoveu a centralização política, de acordo com Mergár (2011, p. 62), não houve tal centralização no que tange à tributação, muito embora "[...] leis referentes a arrecadação de impostos surgiram, como foi o caso da reforma tributária de 1844, realizada pelo ministro da Fazenda, Manuel Alves Branco."

É necessário ter em mente que, mesmo independente, o Brasil foi obrigado a respeitar os tratados firmados no ano de 1810 entre Inglaterra e Portugal e, diante de uma balança comercial desfavorável, cuja importação era superior à exportação, era também obrigado a contrair empréstimos, colocando em risco sua saúde econômico-financeira.

Sem condições de aumentar os impostos provinciais para honrar seus compromissos, a saída encontrada pelo Ministério da Fazenda foi a elevação de tarifas de importação, que ficaram conhecidas como tarifas Alves Branco. Segundo Mergár (2011, p. 63), promover a elevação das tarifas alfandegárias permitiu aumentar a receita dos cofres do governo central, sem onerar os senhores de terras e escravos e, também, “[...] sem limitar a autonomia tributária das províncias".

A autonomia fiscal tributária garantida pelo Ato Adicional e endossada pela Lei de Interpretação do Ato Adicional muito pouco melhorou a situação econômica da província do Espírito Santo. Vários são os relatórios presidenciais que apresentam um discurso ora promissor, ora desanimador - este, suscitado pela pouca renda da província suscitava. Para ilustrar, apresentaremos três excertos de relatórios presidenciais que evidenciam tal contradição. Os dois primeiros pertencem a Luiz Pereira do Coutto Ferraz, que, depois de deixar a presidência da província capixaba, presidiu a província do Rio de Janeiro e, posteriormente, foi nomeado ministro dos Negócios do Império. No seu relatório do ano de 1847, publicado em 1848, ele apresenta que:

[n]ão é desanimador portanto o estado da provincia, pelo que respeita a finanças, pois que a renda tem crescido, e é de esperar que suba no corrente anno. Não tem Ella divida passiva de qualidade alguma, e agora que se acha alliviada de certos encargos, que pesavão sobre seus cofres, pode melhor curar de seus melhoramentos materiaes, de que hão de provir, por certo sua prosperidade e riqueza. Não é avultada a receita, nem chega, é verdade, para

\footnotetext{
${ }^{4}$ Após a abdicação de Pedro I e instaurado o período regencial, em algumas províncias, eclodiram revoltas e/ou manifestações, como a Cabanagem (1835-1840), no Pará, Farroupilha (1835-1845), no Rio Grande do Sul, Sabinada (1837-1838), na Bahia, e Balaiada (1831-1841), no Maranhão. Nesse sentido, conferir Prado Junior (1993).
} 
se fazerem grandes pontes, estradas normaes, e outras obras quantiosas, mas ha com que ir melhorando as vias de communicação ora existentes, e com que se possa tratar de abrir outras estradas para fazer desenvolver, embora lentamente, os germens de riqueza, que a provincia encerra, sobre tudo se forem applicados os meios com a necessária economia, e houver na arrecadação de todas as suas rendas a devida fiscalisação (ESPÍRITO SANTO, 1848a, p. 27, grifo nosso).

No relatório do ano seguinte, publicado no mesmo ano que o anterior, Coutto Ferraz continua tendo esperanças de melhoria das rendas da província e continua afirmando que não havia dívidas passivas. Vejamos um trecho de seu relatório de 1848:

Esperançoso, por sobre lisongeiro, vae se tornando de dia em dia o estado financeiro da província. A receita, comparativamente aos trez últimos annos, tem ido em progressivo augmento. Não estão ainda fechadas as contas do exercício findo no último de dezembro, e sobe já a receita a 46:008\$646 rs. Ora, tendo sido a despeza de Rs. 29:424\$225, passou para o corrente exercício um saldo a favor da receita de RS 16:584\$421. Nada deve a província: seus empregados teem sido sempre pagos em dia, e o mesmo tem acontecido aos empresarios das obras feitas durante o anno passado em todos os municipios. (ESPÍRITO SANTO, 1848b, p. 25).

Pelos excertos apresentados, observamos que Luiz Pereira Coutto Ferraz não apenas tinha esperanças de que as rendas provinciais aumentassem como apresenta uma sobra para o ano de 1848. Além disso, no fragmento referente a 1847, ele chama a atenção de seus ouvintes dizendo que o que se arrecada não é o bastante para a realização de grandes obras, mas que as rendas poderiam ser aumentadas melhorando a fiscalização.

Considerando que a ideia de progresso e modernidade, seja de uma província, seja de uma nação, tem clara relação com a arrecadação de rendas e, naquele momento, eram evidenciados por obras públicas, notamos mais uma vez que a pobreza da província do Espírito Santo era relativa, uma vez que, em função da pouca arrecadação, ela, como as demais, na primeira metade dos oitocentos, era privada de outros recursos materiais, como as ferrovias, símbolo da modernidade e do progresso.

Causa-nos assombro que, em um intervalo de apenas dois anos, o relatório do presidente Felippe José Pereira Leal traga uma carga de pessimismo quando se trata das rendas provinciais e assevere, contrariamente aos relatórios anteriores, que

[é] por certo desanimador o estado deste ramo da publica administração, o qual, convem declarar, antecede a minha posse, [...] Do balanço respectivo vê-se que no anno passado arrecadou-se a quantia de rs. 43:505\$432 e despendeu-se a de $43: 387 \$ 983$, passando para o presente anno um saldo de $117 \$ 449$. [...] 
Salta aos olhos que a arrecadação e fiscalização, que se exerce, nem-um resultado proveitoso appresentão, [...].

Posso assegurarvos, sem o menor receio de ser contestado, que as rendas desta província chegarião para fazer face á suas despesas, e haverião saldo todos os annos, se se procedesse a sua arrecadação com a mais exacta fiscalisação; mas isto será impossível em quanto não authorizardes aquellas providencias (ESPÍRITO SANTO, 1850, p. 33-34, grifo nosso).

O que teria acontecido com as rendas provinciais capixabas? Será que Coutto Ferraz, para apresentar-se como um bom administrador para o estafe imperial ou ainda se valendo de sua força política, "burlou" os números? Ou será que Pereira Leal, com vistas a receber mais do cofre central, pintou a situação provincial como caótica?

Lendo com mais acuidade o excerto do relatório de Pereira Leal, verifica-se que o valor arrecadado das rendas fizeram frente às despesas daquele ano, tendo inclusive um pequeno saldo que, de fato, não poderia ser reinvestido na província. Por certo, havia um forte desejo de elevar a província a uma condição melhor, garantindo também sua ascensão como político e bom administrador, mas, provavelmente, seus intentos foram frustrados.

De acordo com Mergár (2011, p. 98), havia muitos problemas, fosse durante o processo de arrecadação dos impostos, fosse por

[...] repugnância do povo em pagar o imposto, porque os sistemas de tributação eram pouco eficientes, ou devido à falta de servidores, de instalações que facilitassem a cobrança e a fiscalização. [No entanto,] [f]ica mais do que evidente que a província não possuía lastro financeiro que fosse capaz de dar conta de tantas necessidades e reivindicações.

Diante disso, parece conveniente pressupormos que com um planejamento financeiro, como nos dá entender Coutto Ferraz, seguido de uma boa fiscalização, como assevera Pereira Leal, ainda que não houvesse lastro financeiro, a situação da província capixaba seria outra. Não obstante, na prática, ainda que a receita fosse modesta como se alegava, o que era arrecadado, era capaz de honrar seus compromissos para despesas.

\section{CONSIDERAÇÕES FINAIS}

No decorrer do texto, percebemos que, como nos alerta Croce (2015), a história econômica do Brasil deve ser analisada regionalmente com lentes que possam nos proporcionar uma visão mais clara para compreender as especificidades de cada região - estas semelhantes às de outras províncias, mas ainda sim especificidades. Pelo exposto, denotamos que a província do Espírito Santo teve peculiaridades históricas, políticas, econômicas e sociais que a 
singulariza no conjunto do mosaico da região Sudeste, muito embora tais especificidades e singularidades, no aspecto econômico, somente surgiram com maior vigor a partir da segunda metade dos oitocentos, o que foge ao espaço temporal contemplado por este texto.

Durante o período colonial, mesmo sofrendo ataques indígenas ou atendendo às ordens da Coroa, que não lhe permitiram colonizar seu interior, a capitania capixaba desenvolveu sua economia de maneira que, conforme Leal (1977), chegou a produzir cerca de seis mil toneladas de açúcar, garantindo o comércio exterior. Posteriormente, mesmo com a baixa da demanda europeia pelo produto, a província, com a agricultura de subsistência, a exportação da farinha de mandioca e a extração e o comércio da madeira, além do comércio de cabotagem, teve o suporte necessário para garantir o mercado interno, mantendo lubrificadas as engrenagens comerciais do país.

Ainda que ocupando apenas estreita faixa do litoral, a população capixaba, que poderia não ser "industriosa", como vários governantes alegavam, conseguiu garantir uma receita que pudesse honrar seus compromissos. É certo que, como assevera Luiz Pereira Coutto Ferraz, a receita não permitia ter gastos com melhoramento de estradas, transportes, etc. que elevassem a província a outro patamar aos olhos da administração central, apenas quitar suas despesas. Portanto, ela não era rica, mas também não paupérrima, como se alegavae nos documentos governamentais.

O que se depreende dos relatórios provinciais, cujos excertos aqui foram apresentados, é que a província do Espírito Santo não era tão pobre quanto se alegava. Não somente ela, mas qualquer outra província dependia da força política do presidente do momento, pois assim poderia compor o caixa provincial com verbas enviadas pelo governo central, ainda que com atrasos no envio.

Outro ponto que nos chama atenção é a constatação da falta de fiscalização do que era arrecadado e da pouca força policial por falta de servidores, dando brechas para falcatruas e corrupção. Isso acaba gerando um ciclo vicioso, pois, sem verbas para garantir o salário de servidores, por um lado, assistia-se à saída de verbas pela corrupção e, de outro, a falcatruas.

O fato é que, a partir da segunda metade dos oitocentos, o café, juntamente com a migração (tanto estrangeira quanto nacional), reverteu o quadro de "penúria" da economia capixaba. $\mathrm{O}$ contingente de migrantes que se instalou em pequenas propriedades e que teve na cultura do café o sucesso almejado pelos governantes, no decorrer da primeira metade dos oitocentos, foi o diferencial da província do Espírito Santo, que, ao contrário das demais províncias da região Sudeste, teve na exportação do café produzido em pequenas propriedades 
seu principal gênero na balança comercial. Ela contrariou, portanto, a historiografia tradicional de que a cultura do café para exportação somente se deu em latifúndios escravistas das províncias do Rio de Janeiro, de São Paulo e de Minas Gerais.

Nesses rincões, a terra foi imediatamente transformada em mercadoria, como nos ensina Francisco de Oliveira (1983), resolvendo, em parte, a questão das terras devolutas e incultas, além do aumento da mão de obra para o café com os imigrantes, já que o plantel de escravos da província do Espírito Santo, em relação às demais províncias do Sudeste, era pequeno e buscava, sob incentivo de seus senhores, a formação de famílias e relações familiares mais duradouras, garantindo sua procriação e evitando, assim, fugas e rebeliões de escravos (CAMPOS, 2011).

Todavia, é necessário que outras pesquisas sejam realizadas com foco nos períodos colonial e pós-independência até o início da segunda metade dos oitocentos. Uma pesquisa quali-quantitativa utilizando, talvez, como arcabouço metodológico a Micro-História poderia nos fornecer maiores conhecimentos de pequenas comunidades capixabas, já que outras fontes, além dos relatórios provinciais ou memoriais oficiais, como registros de ordens religiosas e jornais, poderiam ser utilizadas.

Tal pesquisa sugerida, cujo objetivo seria o de comparação entre a economia da província do Espírito Santo e outras que tivessem um perfil aproximado, poderia nos esclarecer melhor sobre a situação econômica e social da província capixaba. Não podemos perder de vista que, no período apontado, o Brasil como um todo passou por forte crise política e econômica, e não apenas uma ou outra província.

Observamos que, na capitania e posterior província do Espírito Santo, como nas demais províncias na primeira metade dos oitocentos, sempre houve uma pobreza relativa na medida em que não havia verba suficiente para melhoramentos - e estes, quando materializados, significavam a entrada na esteira do progresso e da modernidade. Assim, acreditamos que, usando lentes que nos possibilitem enxergar melhor a situação econômico-social da província capixaba na primeira metade dos oitocentos, poderemos, paulatinamente, derrubar a imagem de pobreza absoluta construída e perpetuada pelos discursos que alimentou o imaginário capixaba durante a primeira metade do século XIX e se retroalimentou por muitos anos ainda.

\section{REFERÊNCIAS}

ABREU, João Capistrano de. Capítulos de História Colonial. Belo Horizonte: Itatiaia, 1988. 
BARROS, José D’Assunção. História, região e espacialidade. Revista de História Regional, Ponta Grossa, PR, v. 10, n. 1, p. 95-125, 2005.

BITTENCOURT, Gabriel. Café e modernização: o Espírito Santo no século XIX. Rio de Janeiro: Livraria Editora Cátedra, 1987.

CAMPOS, Adriana Pereira. Escravidão, reprodução endógena e crioulização: o caso do Espírito Santo no Oitocentos. Topoi, Rio de Janeiro, v. 12, n. 23, p. 84-96, jul./dez. 2011.

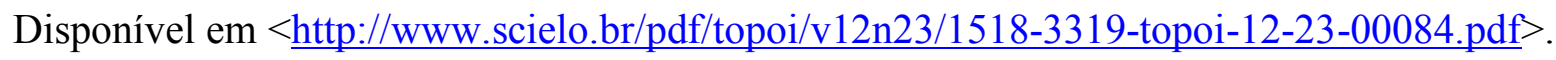
Acesso em 30 mar. 2016.

CARVALHO, Enaile Flauzina. Política e economia mercantil nas terras do Espírito Santo (1790 a 1821). 2008. 160 f. Dissertação (Mestrado em História Social das Relações políticas)-Centro de Ciências Humanas e Naturais, Universidade Federal do Espírito Santo, Vitória, 2008.

CODES, Ana Luiza Machado de. Modelagem de equações estruturais: uma contribuição metodológica para o estudo da pobreza. 2005. 297 f. Tese (Doutorado em Ciência Sociais)Universidade Federal da Bahia, Salvador, 2005. Disponível em $<$ http://repositorio.ufba.br/ri/handle/ri/11012>. Acesso em: 23 abr. 2017.

CROCE, Marcus Antônio. A economia do Brasil no século XIX. In: CONGRESSO BRASILEIRO DE HISTÓRIA ECONÔMICA, 11, 2015, Vitória - ES: Anais eletrônicos.

DAEMON, Basílio. Província do Espírito Santo: sua descoberta, história cronológica, sinopse e estatística. 2. ed. Vitória: Secretaria de Estado da Cultura; Arquivo Público do Estado do Espírito Santo, 2010.

ESPÍRITO SANTO. Assembleia Legislativa Provincial. Relatório do Presidente da Província do Espírito Santo, o doutor Luiz Pedreira do Coutto Ferraz na abertura da assembléa legislativa provincial no dia 23 de maio de 1847. Rio de Janeiro, Typ. do Diario, de N. L. Vianna. 1848a. 
ESPÍRITO SANTO. Assembleia Legislativa Provincial. Relatório do Presidente da Província do Espírito Santo, o doutor Luiz Pedreira do Coutto Ferraz na abertura da assembléa legislativa provincial no dia $1^{\circ}$ de março de 1848. Rio de Janeiro, Typ. do Diario, de N. L. Vianna. 1848b.

ESPÍRITO SANTO. Assembleia Legislativa Provincial. Relatório do Presidente da Província do Espírito Santo, o Exm Sr. Filippe José Pereira Leal abriu a sessão ordinária da respectiva assembléa legislativa, no dia 25 de julho do corrente ano. Victoria, Typ. Capitaniense de P.A. D’Azeredo. 1850.

FAORO, Raymundo. Os donos do poder: formação do patronato político brasileiro. Porto Alegre: Globo, 1958.

FARIA, Sheila de Castro. A colônia em movimento: fortuna e família no cotidiano colonial. Rio de Janeiro: Nova Fronteira, 1998.

KOSELLECK, Reinhart. Futuro Passado: contribuição à semântica dos tempos históricos. Tradução: Wilma Patrícia Maas e Carlos Almeida Pereira. Rio de Janeiro: Contraponto: Ed. PUC-Rio, 2006.

LEAL, João Eurípedes Franklin. Economia colonial capixaba. Revista Cuca Cultura Capixaba, Vitória, ES, n. 0, fev. 1977.

MATTEI, Lauro. A persistência da pobreza no Brasil. In: SEMINÁRIO INTERNACIONAL POLÍTICAS TERRITORIAIS E POBREZA NO CAMPO E NA CIDADE. 2014, Rio de Janeiro. Mesa 3 - Territorialização, pobreza e exclusão a persistência da pobreza no Brasil. Rio de Janeiro, 2014.

MERGÁR, Eucélia Maria Agrizzi. Repartição da competência tributária no Império e seus efeitos na Província do Espírito Santo (1836-1850). 117 f. Dissertação (Mestrado em História)-Universidade Federal do Espírito Santo, Centro de Ciências Humanas e Naturais, 2011. 
NARDOTO, Eliezer; LIMA, Herineia. História de São Mateus. São Mateus: EDAL, 1999.

OLIVEIRA, Francisco. A questão regional: a hegemonia inacabada. Estudos Avançados, São Paulo, v. 7, n. 18, 1983.

Crítica à razão dualista/O ornitorrinco. São Paulo: Boitempo,

2003.

OLIVEIRA, José Teixeira. História do Espírito Santo. 3.ed. Vitória: Arquivo Público do Estado do Espírito Santo/Secretaria de Estado da Cultura, 2008.

PRADO JUNIOR, Caio. Formação do Brasil contemporâneo (colônia). 6. ed. São Paulo: Brasiliense, 1961.

. Evolução política do Brasil: Colônia e Império. 20. ed. São

Paulo: Brasiliense, 1993.

RUBIM, Francisco Alberto. Memorias para servir à historia até ao anno de 1817, e breve noticia estatistica da capitania do Espírito Santo, porção integrante do reino do Brasil, escriptas em 1818, e publicadas em 1840 por um capixaba. Lisboa: Nevesiana, 1840.

SAINT-HILAIRE, Auguste de. Segunda viagem ao interior do Brasil - Espírito Santo. Tradução: Carlos Madeira. São Paulo: Cia Editora Nacional, [1936]. p. 29

VASCONCELOS, Accioli de. Memoria Statistica da Província do Espírito Santo escrita no ano de 1828. Transcrição do manuscrito original realizada por Fernando Achiamé. Vitória: Arquivo Público do Estado do Espírito Santo, 1978. 